\title{
Progressive growth of a cystic lesion near the pancreatic head
}
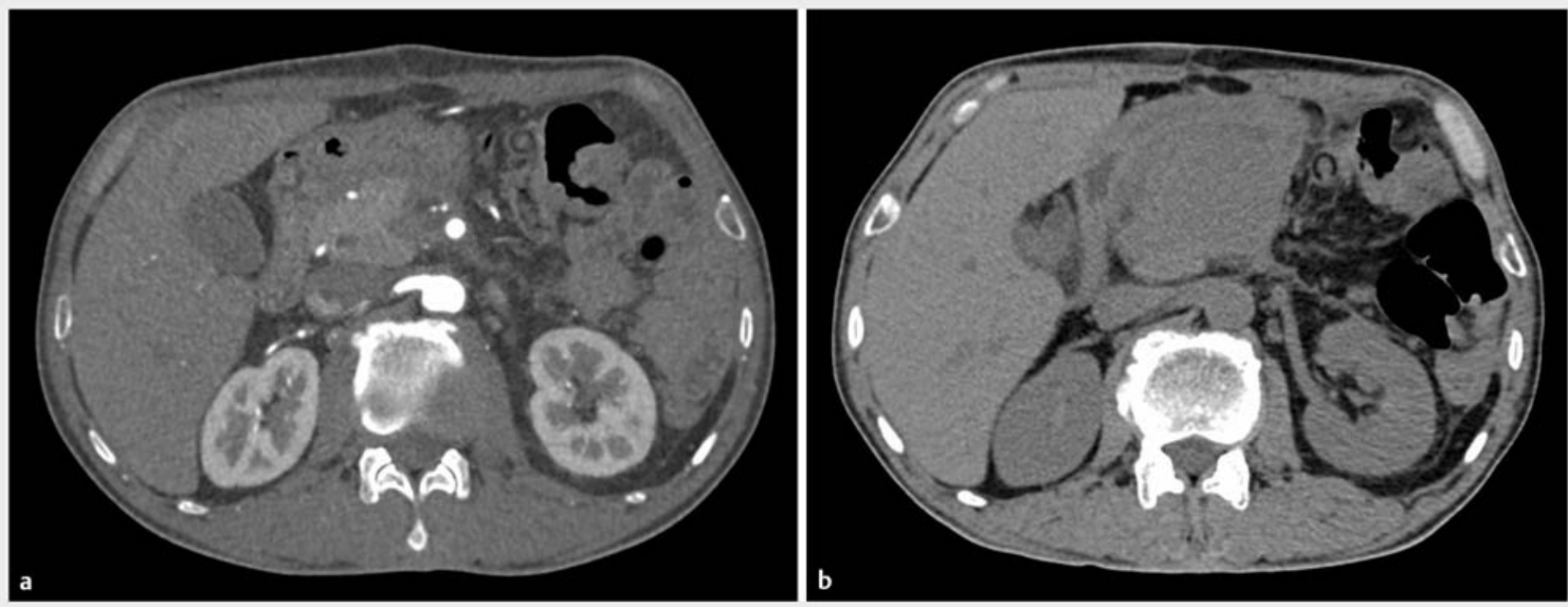

- Fig. 1 Enhanced computed tomography (CT). a A blurred, fat space in front of the pancreatic head was seen, with swelling of the intestinal wall. $\mathbf{b}$ Repeat $C T$ showed a round, low-density mass (diameter $4.6 \mathrm{~cm}$ ) near the pancreatic head.

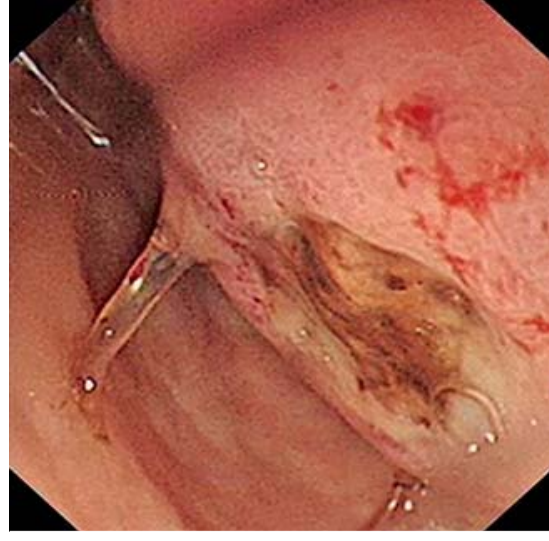

Fig. 2 Endoscopy revealed a large protuberance in the posterior wall of the antrum, with several ulcers on the surface.

A 56-year-old man was admitted to hospital because of upper abdominal pain and mild fever for 2 weeks. One month previously, the patient had undergone resection of the body and tail of the pancreas and splenectomy for pancreatic malignant tumor, and 2 weeks ago, the patient experienced abdominal pain with mild fever. Enhanced computed tomography $(\mathrm{CT})$ showed a blurred fat space in
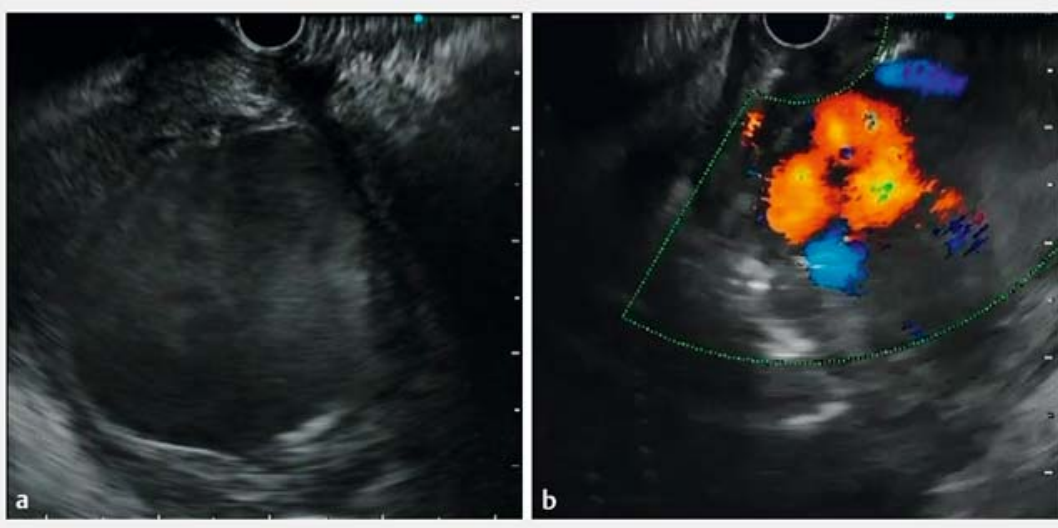

- Fig. 3 Endoscopic ultrasound. a An elliptical, uneven, hypoechoic mass was seen near the pancreatic head, with fluid movement within the mass. b Color Doppler showed disorder of blood flow within the mass.

front of the pancreatic head and swelling of the intestinal wall ( $\triangleright$ Fig.1a). The symptoms gradually worsened and vomiting occurred a few days before admission. Repeat CT showed a round, low-density mass (diameter $4.6 \mathrm{~cm}$ ) near the pancreatic head ( $\triangleright$ Fig.1 b). Clinicians considered the diagnosis of pancreatic pseudocyst with infection. Endo- scopic ultrasonography (EUS)-guided cyst aspiration was planned.

Endoscopy revealed a large protuberance in the posterior wall of the antrum, several ulcers on the surface ( $\bullet$ Fig. 2 ), and stenosis of the antrum. EUS showed an elliptical, uneven, hypoechoic mass near the pancreatic head ( $\mathbf{F i g . 3 a}$ ), and fluid movement within the mass. 


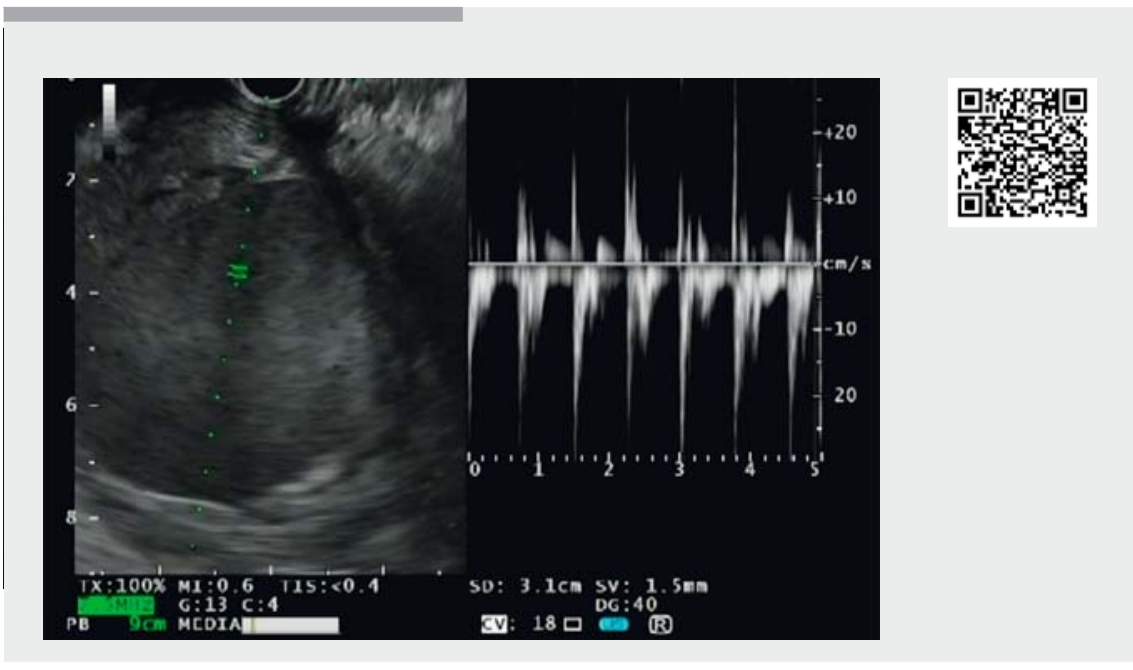

Video 1 Pseudoaneurysm was diagnosed by endoscopic ultrasonography using color Doppler and pulse Doppler.

Color Doppler ultrasound showed disorder of blood flow within the mass ( $\vee$ Fig.3b), and pulse Doppler ultrasound detected different types of blood flow ( $\triangleright$ Video 1$)$. A diagnosis of pseudoaneurysm was confirmed.

The patient underwent emergency surgery. Massive hematemesis occurred after tracheal intubation under general anesthesia. Immediate laparotomy confirmed a pseudoaneurysm of the celiac artery trunk, which had ruptured into the gastric cavity; successful repair was performed.

Pancreatic pseudoaneurysms are rare complications of acute or chronic pancreatitis [1]. Surgery is another cause of pancreatic pseudoaneurysm [2]. The main clinical symptom is abdominal or digestive tract hemorrhage, with a high mortality rate. Contrast-enhanced CT angiography and digital subtraction angiography are the main methods used to diagnose pancreatic pseudoaneurysm [3]. EUS is also an effective method of diagnosis.

Endoscopy_UCTN_Code_CCL_1AZ_2AO

\section{Acknowledgement}

The authors want to thank Sichuan Province Science and Technology Department (China) (2018SZ0134) for their support.

\section{Competing interests}

The authors declare that they have no conflict of interest.

The authors

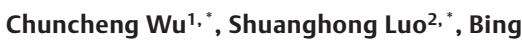
$\mathrm{Hu}^{1}$

1 Department of Gastroenterology, West China Hospital, Sichuan University, Chengdu, Sichuan, China

2 Department of Pediatrics, West China Second University Hospital, Sichuan University, Chengdu, Sichuan, China

Corresponding author

\section{Bing Hu, MD}

Department of Gastroenterology, West China Hospital, Sichuan University, No. 37 Guo Xue Xiang, Chengdu, Sichuan, 610041, China

Fax: +86-28-85423387

hubingnj@163.com

\section{References}

[1] Pillay WR, Lalloo S, Thomson SR et al. Embolisation of metachronous pseudoaneurysms complicating chronic pancreatitis. HPB (Oxford) 2003; 5: 251-253

[2] Lubezky N, Goykhman Y, Nakache R et al. Early and late presentations of graft arterial pseudoaneurysm following pancreatic transplantation. World J Surg 2013; 37: 1430-1437

[3] Bartosz Z, Nattakarn L, Marte J et al. Endovascular management of pancreatitis-related pseudoaneurysms: a review of techniques. Plos One 2018; 13: e0191998

\section{Bibliography}

DOI https://doi.org/10.1055/a-1085-9413

Published online: 22.1.2020

Endoscopy 2020; 52: E239-E240

(C) Georg Thieme Verlag KG

Stuttgart · New York

ISSN 0013-726X

\section{ENDOSCOPY E-VIDEOS \\ https://eref.thieme.de/e-videos}

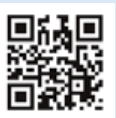

Endoscopy E-Videos is a free access online section, reporting on interesting cases and new

techniques in gastroenterological endoscopy. All papers include a high quality video and all contributions are freely accessible online.

This section has its own submission website at

https://mc.manuscriptcentral.com/e-videos

\footnotetext{
* These authors contributed equally to this work.
} 